\title{
Marketing of environmentally friendly hotels in China through religious segmentation: a theory of planned behaviour approach
}

\author{
Lei Wang and Philip Pong Weng Wong
}

\begin{abstract}
Purpose - The purpose of this study is to examine the relationship between religiosity, green purchase attitude (GPA), subjective norm (SN), perceived behavioural control (PBC) and green purchase intention (GPI) towards the selection of environmentally friendly hotel. The current study argues that consumers' incentive variable, namely, religiosity, can influence consumers' environmentally friendly hotel selection.
\end{abstract}

Design/methodology/approach - This study had successfully gathered 404 completed questionnaire sets through online surveys. All survey data were subjected to descriptive analysis and analysis of variance using SPSS. Besides that, confirmatory factor analysis and structural equation modelling were performed for the testing of hypotheses.

Findings - The results suggest that religiosity significantly and positively influences GPA, SN, PBC and GPI. Furthermore, GPA and PBC positively and significantly influence GPI. The SN also displays significant positive influence on GPA, while GPA plays a full mediation role between SN and GPI. In addition, statistically significant differences in religiosity, $S N$ and $P B C$ were obtained between religious affiliations of consumers towards environmentally friendly hotel selection.

Originality/value - This study extended the existing knowledge based on the selection of environmentally friendly hotels among religious consumers in the tourism literature. Besides that, these empirical findings would greatly benefit hotel managers and other key stakeholders in the tourism industry.

\section{Introduction}

Green purchase behaviour is closely linked to acquiring products and services that contribute to the least negative effects on the environment throughout their life cycle (Vazifehdoust et al., 2013). The green marketing concept already began back in Second World War or even before the war (Muzaffar, 2015). Green purchase behaviour has gained growing research interest, especially on identifying key predictors of consumer behaviour (Mas'od and Chin, 2014). Through the growth of green awareness, the intention to purchase green services and products and the participation in pro-environmental practices are higher (Teeroovengadum, 2019). Sutikno and Margaretha (2020) highlight a similar notion on the gradual adaptation of the current consumers to pay more for naturally benevolent products and services and adopt a diverse range of environmentally friendly practices.

In the hotel industry, more consumers demand environmentally friendly facilities and services (Wang et al., 2020) as a result of their concern on the negative implications of resource overconsumption and waste production (Wang et al., 2019a). Hence, hotel
Lei Wang is Lecturer at the Faculty of Hospitality and Tourism, School of Management, Xuzhou University of Technology, Xuzhou, China.

Philip Pong Weng Wong is Senior Lecturer at School of Hospitality, Sunway University, Kuala Lumpur, Malaysia.

Received 3 August 2019 Revised 1 October 2019 14 December 2019 31 January 2020 26 March 2020 8 May 2020 15 May 2020 16 May 2020 Accepted 17 May 2020 
marketers are driven to continuously develop and improve green practices and green initiatives (Han et al., 2010). Despite the promising trend of green purchase attitude (GPA) among consumers in selecting environmentally friendly hotels (Kasliwal and Agarwal, 2015; Rahman and Reynolds, 2016), revenues and bookings received by environmentally friendly hotels have remained stagnant (Mas'od and Chin, 2014; Mohamad et al., 2014).

Despite the significant expansion of environmentally friendly hotels in China (more than 700 environmentally friendly hotels), various industry research reports and empirical studies revealed low levels of concern and understanding on environmentally friendly hotels among Chinese consumers (Jiang and Gao, 2019). Moreover, green purchase behaviour was extensively explored from the Western perspectives (Wang et al., 2019a). There are limited findings on the environmentally friendly hotel selection in China, resulting in the lack of a standardised definition and coherent foundation (Wang et al., 2019b).

Many studies incorporated the theory of reasoned action (TRA) (Ajzen and Fishbein, 1975) and theory of planned behaviour (TPB) (Ajzen, 1991) to understand how attitude affects intention in the context of green behaviour (Han, 2015; Paul et al., 2016). Beliefs and attitudes are translated into actual behaviours according to these theories but most cases revealed otherwise (Chatzidakis et al., 2007). In fact, the nature of the relationship of beliefs, attitudes and actual behaviour is complex. Apart from the influence of beliefs and attitudes on behaviour, various factors affect one's behaviour (Chatzidakis et al., 2007).

Religiosity reflects one's adherence to religious principles, convictions and rituals in routine (Worthington et al., 2003). The influence of religiosity on certain behaviours is recognised (Martin and Bateman, 2014) but only a few studies empirically tested the role of religiosity as a precondition to comprehend attitudes and behaviours pertaining to green consumption (Mas'od and Chin, 2014; Wang et al., 2019b). Moreover, how religiosity is linked to consumers' green consumption, such as the selection of environmentally friendly hotels in a non-Western context has been underexplored (Wang et al., 2019b).

The current study had assessed the influence of religiosity on the different TPB components, specifically on how attitude and intention influence consumers' selection of environmentally friendly hotels in China. This study offers valuable and new insights from an Asian perspective. Accordingly, this study also extended the existing knowledge based on the influence of religiosity, GPA, subjective norm (SN), perceived behavioural control (PBC) and intention on the selection of environmentally friendly hotels among consumers.

\section{Literature review}

\subsection{Underpinning theories of study}

This study adopted TPB (Ajzen, 1991), which is incorporated in the conceptual model (Figure 1). TRA and TPB are among the most prominent behavioural theories in the field of marketing (Paul et al., 2016; Wang et al., 2019b). Both theories are frequently used as models to assess consumers' green purchase intention (GPI) or actual behaviour (Rahman and Reynolds, 2016; Paul et al., 2016) and the relationships of beliefs or values, attitude, behavioural intention and actual behaviour (Ajzen, 1991; Coleman et al., 2011). Both theories allow the means to explore the impact of other contextual variables which might help to explain behaviour (Chen and Tung, 2014; Kumar et al., 2017). The inclusion of religiosity as part of the proposed conceptual model was considered in this study given the flexible nature of TPB.

There are concerns on the relevance of TRA in predicting attitude and non-volitional components of behaviour given its theoretical emphasis over volitional control and disregard of the control over key opportunities and resources (Paul et al., 2016). The limitations of TRA in overlooking non-volitional aspects of behaviour were addressed through the inclusion of PBC, resulting in the formation of TPB (Ajzen, 1991; Wang et al., 2019c). Attitude, SN and 


\section{Figure 1 Conceptual research model}

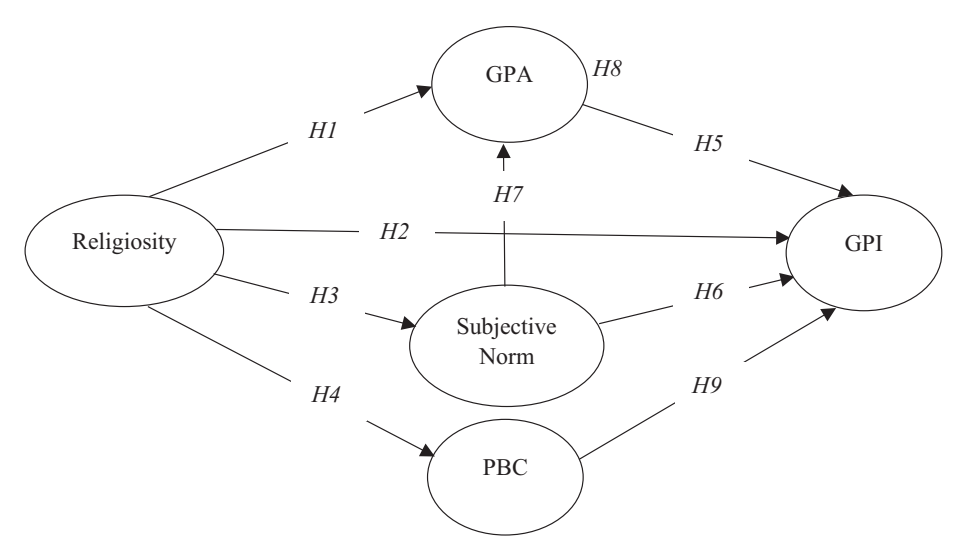

Notes: Green purchase attitude (GPA); perceived behavioural control $(\mathrm{PBC})$; green purchase intention (GPI)

PBC are postulated to influence behavioural intention and eventually, the actual behaviour. Thus, referring to TPB, GPI predicts green purchase behaviour (Chen and Tung, 2014; Paul et al., 2016).

\subsection{Religiosity}

In the past three decades, studies have explored how cultural factors influence consumer behaviour. As an important subcultural factor, religion plays a highly significant role in effecting consumer behaviour (Ahmad et al., 2015; Madni et al., 2016), because consumers exhibit their beliefs through their consumption choices (Lari et al., 2019). Past studies conceptualised religion as being a simple construct with religious affiliation (Mokhlis, 2009). Basically, religious affiliation reflects one's personal identification or strong beliefs towards specific religious orders (Madni et al., 2016). Religious affiliations could significantly influence consumers' purchase attitudes and behaviours (Guo et al., 2013; Suki and Suki, 2015), but other scholars have highlighted the inappropriateness of using this measure to examine behaviour in the decision-making process of consumers because it compromises validity given its unidimensional measurement (Mokhlis, 2009).

As previously described, religiosity reflects the extent of adherence to religious principles, convictions and rituals in one's routine (Worthington et al., 2003). According to De Run et al. (2010), religiosity is a multifaceted concept that integrates various aspects of experiences, beliefs and practices. In marketing, intrinsic and extrinsic religiosity influences the attitude and behaviour of consumers (Wang et al., 2019b). Intrinsic religiosity refers to one's stance on religious views, virtues and practices (Madni et al., 2016), while extrinsic religiosity is linked to religious associations, sacred rituals and members of a spiritual society (Borzooei and Asgari, 2014).

According to Shin et al. (2011), religiosity affects one's purchase behaviour, which acts as a precursor of demand. There are various patterns of religious values since childhood - for instance, the development of encounters and supplementary education, languages and socioeconomic characteristics that accommodate the changing lifestyle and conditions of an individual (Madni et al., 2016). Taking the case of Islam, Muslims can only purchase or consume halal products or services. This reflects the influence of religiosity on consumers 
as well as their undeviating stance and adherence to the religious values over an extended period (Khraim, 2010; Wang et al., 2019b).

Certain studies revealed how religiosity significantly influences the pro-environmental attitude and behaviour of consumers. According to Minton et al. (2015), Christianity, Islam and Judaism noted that God created nature, where God and mankind have a grander status over nature, whereas Buddhism, Hinduism and Taoism viewed God in everything, including nature itself. Certain studies found that Buddhism and Hinduism positively affected pro-environmental behaviour (Mawdsley, 2004; Minton et al., 2015; Wang et al., 2019b). Wang et al. (2019b) link the concepts or doctrines of pro-environment significance to different religions - Buddhism focuses on "karma"; Islam views Earth as "a sacred and holy place"; Taoism stresses on the notion of "humankind and nature"; and Protestantism and Catholic emphasise on "nature and human responsibility".

Previous green marketing studies discovered various contexts that were found to reinforce the relationships of religiosity, attitude, intention and behaviour among consumers (Engelland, 2014; Kirmani and Khan, 2016). For instance, Wang et al. (2019b) found highly religious tourists in China displayed a positive attitude towards environmentally friendly hotel selection. According to Minton et al. (2015), religiosity was found to significantly and positively influence different sustainable behaviours (green purchase behaviour and disposal behaviour). Meanwhile, Martin and Bateman (2014) reported a significant and negative relationship between religiosity and GPA among 416 Judeo-Christians. Based on the above findings, the following hypotheses were proposed for testing:

H1. There is a positive significant relationship between religiosity and GPA.

H2. There is a positive significant relationship between religiosity and GPI.

According to Wang et al. (2019c), SN refers to one's normative beliefs on the sense of right and wrong and the underlying reasons to adhere to the beliefs. There is a certain sense of importance when it comes to influencing the close members of one's social circle, which can include family members, relatives, business partners, colleagues and close friends (Paul et al., 2016). For certain individuals, it can be the members of a certain religion as they share common qualities (e.g. beliefs, principles or values). SN can either positively or negatively influence one's behavioural intention. Considering the influence of the expectations of others (e.g. religiosity) on one's SN, the following hypothesis was established for testing:

H3. There is a positive significant relationship between religiosity and SN.

Religiosity appears to have a significant value in one's cognitive structure, which can affect behaviour (Lau, 2010). Highly religious individuals are postulated to view the world from religious perspectives, as religion is incorporated into their daily life (Patel, 2012). Unlike those who display a lower level of religiosity, this group of individuals are more likely to be doctrinaire and conventional. They are also likely to act according to their religious principles and customs (Choi, 2010). Moreover, these highly devoted worshippers adeptly act and behave in a manner or choice that reflects their religious morals and doctrines. With the high level of religiosity, the perceived expectations from their religious proenvironmental doctrines can lead to positive PBC. Thus, the following hypothesis is proposed:

H4. There is a positive significant relationship between religiosity and PBC.

\subsection{Green purchase attitude}

Attitude describes one's evaluation of a given behaviour (e.g. positive vs negative evaluation and favourable vs unfavourable evaluation) (Ajzen, 1991). It is also plausible that attitude reflects one's psychological evaluation of a specific product or services 
(Maichum et al., 2016). Regardless of whether a specific behaviour is performed, attitude incorporates one's evaluation of the behaviour (e.g. good, bad or indifferent) (Paul et al., 2016). Attitude reflects the unchanging preference or state of mind towards a particular behaviour or point of view (Aman et al., 2012).

Numerous studies on green behaviour have demonstrated how attitude positively influences behaviour (Paul et al., 2016; Teeroovengadum, 2019). Han et al. (2010) found that attitude significantly and positively affected intention in the context of environmentally friendly hotel selection in the USA and Maichum et al. (2016) reported similar results in Thailand. Likewise, Wang et al. (2019c) adopted the TPB model and found that attitude positively affected intention in the selection of environmentally friendly hotels among 261 Web-based sampled respondents in China. Thus, the following hypothesis was proposed:

H5. There is a positive significant relationship between GPA and intention.

\subsection{Subjective norm}

Ajzen (1991) defined $\mathrm{SN}$ as the driving social force of whether to perform a specific behaviour. It also refers to the perceived views of significant others (e.g. business partners, peers, colleagues or relatives) that would affect one's decision or choice (Chen and Tung, 2014). Han et al. (2010) found that SN significantly and positively affected intention to visit environmentally friendly hotels. Likewise, Chen and Tung (2014) found a significant and positive relationship between $\mathrm{SN}$ and intention to visit environmentally friendly hotels in Taiwan. In addition, Muzaffar (2015) highlighted the high explanatory power of SN as a determinant of GPI in Pakistan. In line with the finding of these prior studies, the following hypothesis was proposed:

H6. There is a positive significant relationship between SN and consumer GPI.

Certain studies have highlighted a significant causative path from $\mathrm{SN}$ to attitude and subsequently, behavioural intention (Chen and Chai, 2010; Wang et al., 2019c). It is likely that the favourable (or unfavourable) views or perceived novelty of the significant others (referents) on environmentally friendly hotels contributes to one's positive (or negative) GPA (Wang et al., 2019c), while their good/bad experience in green issues contributes to higher or lower GPI.

Chen and Chai (2010) demonstrated a significant influence of SN on GPA among 184 Malaysian undergraduates while Han et al. (2010) found that SN positively and indirectly affected intention of opting for environmentally friendly hotels. Another study by Wang et al. (2019c) found that SN partially mediated the relationship between attitude and intention to visit green hotels in China. Hence, the following hypotheses were developed for testing:

H7. There is a positive significant relationship between $\mathrm{SN}$ and consumer GPA.

H8. GPA mediates the relationship between SN and GPI.

\subsection{Perceived behavioural control}

Ajzen (1991) defined PBC as one's perceived difficulty in performing a particular behaviour. PBC also considers the degree of perceived control over certain factors that potentially prompt one's involvement in an activity (Han et al., 2010). One tends to perform a specific behaviour when the difficulties of performing the behaviour can be handled (Chen and Tung, 2014).

Previous studies postulated the significant role of PBC in influencing consumer behaviour in diverse settings (Albayrak et al., 2013; Chen and Tung, 2014; Paul et al., 2016). For instance, a study by Paul et al. (2016) found that PBC significantly and positively influence intention, which was also in line with the study by Yadav and Pathak (2016). Another study 
by Chen and Tung (2014) found that PBC positively and significantly affected the intention to visit environmentally friendly hotels. Hence, the following hypothesis was tested:

H9. There is a positive significant relationship between PBC and consumer GPI.

\section{Methodology}

\subsection{Data collection}

A non-probability sampling method was selected for this study as it is challenging for social science studies of this nature to acquire a precise sampling frame (Saunders et al., 2011). A purposive sampling technique was performed to gather samples that fit the nature and objectives of the study (Neuman, 2002).

An online survey in the Chinese language was posted online from 1 October 2018 to 31 December 2018 and from 1 November 2019 to 1 December 2019 at the following website: www.wenjuan.com. This free online platform is widely known among individuals, businesses and organisations in China to gather primary data from online users (Wang et al., 2019c). For a variety of research programs, money (i.e. RMB 5) is offered as a fundamental incentive increment to the response rate in which potential participants browse the website for prizes, or they may be invited to complete a questionnaire on the website via email.

For structural equation modelling (SEM), most studies suggested a sample size of at least 200 respondents, and between 10 and 20 cases per parameter (Tabachnick and Fidell, 2007; Kline, 2015). Based on a widely used Cochran formula for an unknown number of the target population, a minimum sample size of 384 respondents is recommended (Burstein, 2011; Sarmah et al., 2013). For this study, 404 respondents were gathered, which exceeded the minimum number of sample size. A pilot test was conducted involving 40 respondents to ensure the usability and validity of the developed instrument and to prevent any problems that may affect the quality of the obtained data. The obtained sample size for the pilot test in this study exceeded the suggested sample size for a pilot test in most studies, which is $10 \%$ of the target sample size for the actual data collection (Hill, 1998; Connelly, 2008).

\subsection{Research instrument}

The research instrument for this study consists of a self-administered and closed-ended questionnaire that included validated measurement scales (De Vaus, 2013). There were four sections in the questionnaire. The first section focused on the religiosity construct, where ten items were adopted from Worthington et al. (2003). The second section focused on the different components of TPB: GPA (five items); SN (three items); and PBC (three items). All items in this section were adapted from past studies (Han et al., 2010; Chen and Tung, 2014; Han and Yoon, 2015). Meanwhile, the third section focused on GPI, where four items were also adapted from past studies (Baker et al., 2013; Chen and Tung, 2014; Han and Yoon, 2015). The final section is related to the demographic characteristics of the respondents. For this study, a five-point Likert scale was used to generate marginally higher mean scores and to allow more straightforward data comparison (Dawes, 2008).

\section{Data analysis and results}

SPSS (version 19) was used to perform descriptive analysis and analysis of variance (ANOVA) for this study while confirmatory factor analysis (CFA) and SEM were conducted using AMOS.

\subsection{Descriptive analysis}

Table 1 displays the descriptive statistics for the demographic characteristic of the sample. 


\begin{tabular}{llrr}
\hline Table 1 Sample characteristics $(N=404)$ & & \\
\hline Items & Characteristics & Frequency & (\%) \\
\hline Gender & Male & 199 & 49.3 \\
Age & Female & 205 & 50.7 \\
& Below 18 & 61 & 15.1 \\
& $18-30$ & 246 & 60.9 \\
& $31-45$ & 69 & 17.1 \\
& $46-60$ & 21 & 5.2 \\
Income level & Above 61 & 7 & 1.7 \\
& Below 1,700 & 90 & 22.3 \\
& $1,701-3,000$ & 89 & 22.0 \\
& $3,001-4,500$ & 116 & 28.7 \\
Education level & $4,501-6,000$ & 54 & 13.4 \\
& Above 6,001 & 55 & 13.6 \\
& Middle school & 24 & 5.9 \\
& High school & 37 & 9.2 \\
& Diploma (3-years) & 128 & 31.7 \\
Religious affiliation & Bachelor (4-years) & 185 & 45.8 \\
& Masters and above & 30 & 7.4 \\
& Buddhism & 96 & 23.8 \\
& Catholicism & 58 & 14.4 \\
& Protestantism & 75 & 18.6
\end{tabular}

This study successfully gathered 404 completed questionnaire sets for analysis. Most of the respondents were female (50.7\%) and between 18 and 30 years of age (60.9\%). In addition, $28.7 \%$ of the total respondents reported monthly income from CNY 3,001-4,500. There were approximately $45.8 \%$ of the total respondents who completed a four-year bachelor's degree. Most importantly, $31.2 \%$ were Taoists.

\subsection{Confirmatory factor analysis}

Cronbach's alpha value of equal to or above 0.7 is considered adequate for the testing of reliability (Hair et al., 2010). As shown in Table 2, items with low factor loadings (i.e. IR1, IR2, ER4, GPA1 and GPI1) were removed before finalising the validity and reliability of the remaining items. Accordingly, the proposed cut-off value in determining the significance of the standardised factor loadings is 0.5 , where 0.7 and above represents the ideal range (Hair et al., 2010). For the current study, all factor loadings exceeded 0.7 .

On the other hand, when it comes to the determination of convergent validity for the measurement model, composite reliability (CR) of above 0.7 and average variance extracted (AVE) of above 0.5 are suggested (Hair et al., 2010). Meanwhile, the discriminant validity of the model can be determined based on average shared squared variance (ASV) and maximum shared squared variance (MSV) - both values should not be higher than AVE (Hair et al., 2010; Byrne, 2016). For the measurement model, the correlation coefficient between different variables under study must be lower than 0.9 (Meyers et al., 2006). With that, Table 3 illustrates the results of discriminant validity.

Following that, the study ensued with the assessment of model fit. Referring to the presented model fit summary, CMIN/DF of $2.053(<3.0)$, goodness of fit index (GFI) of 0.915 , adjusted goodness of fit index (AGFI) of 0.909 , incremental fit index (IFI) of 0.908 , comparative fit index (CFI) of 0.917 , root mean square residual (RMR) of 0.051 , parsimony normed fit index (PNFI) of 0.764 , parsimony comparative fit index (PCFI) of 0.764 and root mean square error of approximation (RMSEA) of 0.046 demonstrated adequate model fit 
Table 2

Construct validity

Factor (Cronbach's alpha) Item

Item

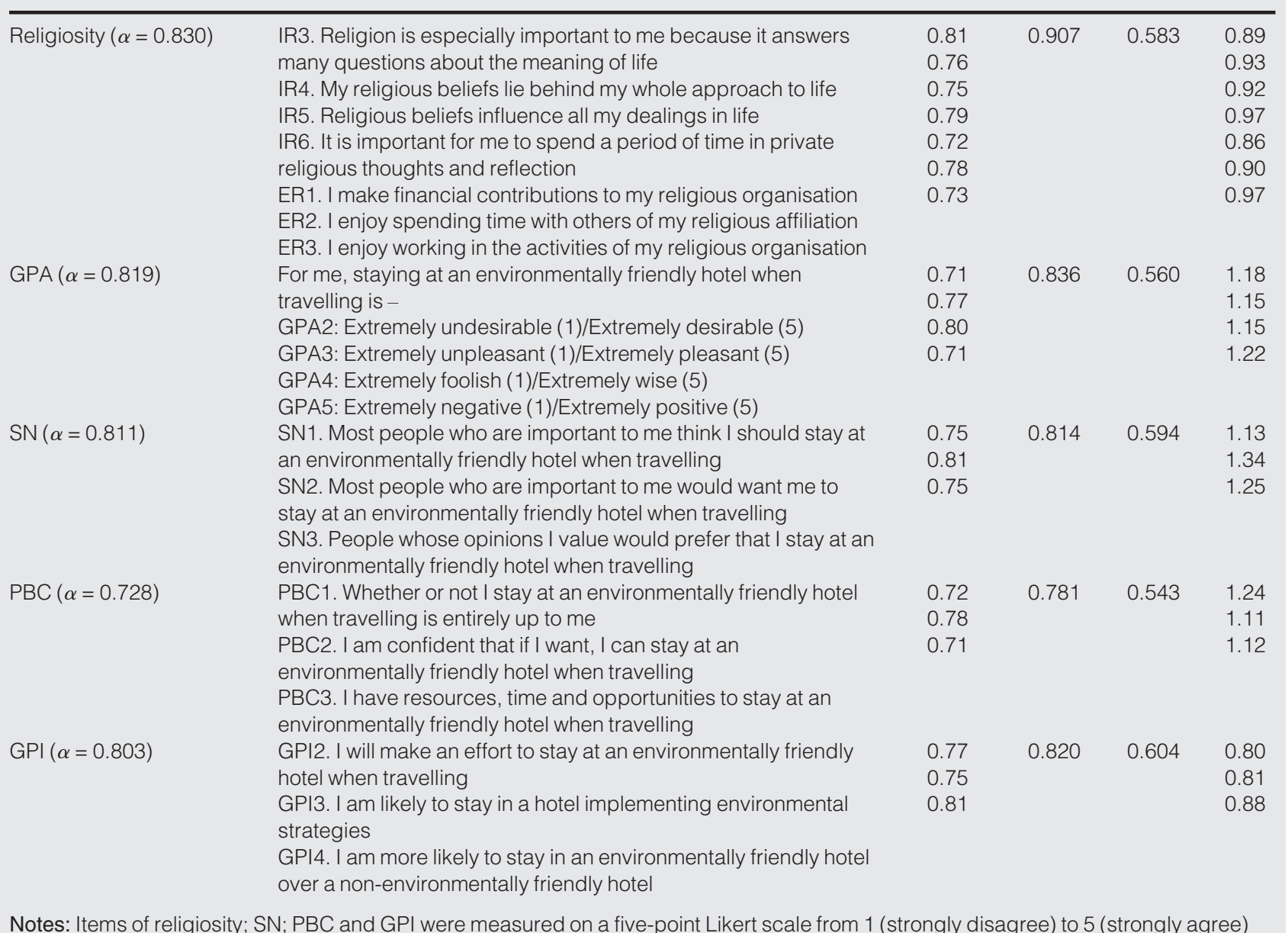

Notes: Items of religiosity; SN; PBC and GPI were measured on a five-point Likert scale from 1 (strongly disagree) to 5 (strongly agree)

Table 3 Discriminant validity

\begin{tabular}{lllllllll} 
Research construct & 1 & 2 & 3 & 4 & 5 & AVE & MSV & ASV \\
\hline 1. PBC & 1 & & & & & 0.543 & 0.445 & 0.200 \\
2. Religiosity & 0.095 & 1 & & & & 0.583 & 0.009 & 0.005 \\
3. GPA & 0.588 & 0.046 & 1 & & & 0.560 & 0.364 & 0.188 \\
4. SN & 0.667 & 0.003 & 0.603 & 1 & & 0.594 & 0.445 & 0.202 \\
5. GPI & 0.019 & 0.086 & 0.203 & 0.006 & 1 & 0.604 & 0.041 & 0.012
\end{tabular}

(Hair et al., 2010). According to Ho (2006), the assessment of model fit requires that at least three indices must be satisfied. Hence, this study proved an adequate model fit.

\subsection{Structural equation modelling}

For the assessment of the structural model and testing of the proposed hypotheses, SEM was performed. The overall goodness-of-fit recorded CMIN/DF of 2.055, RMR of 0.060, AGFI of 0.849 , CFI of 0.914 , GFI of 0.911 , IFI of 0.912 , PNFI of 0.764 , PCFI of 0.872 and 


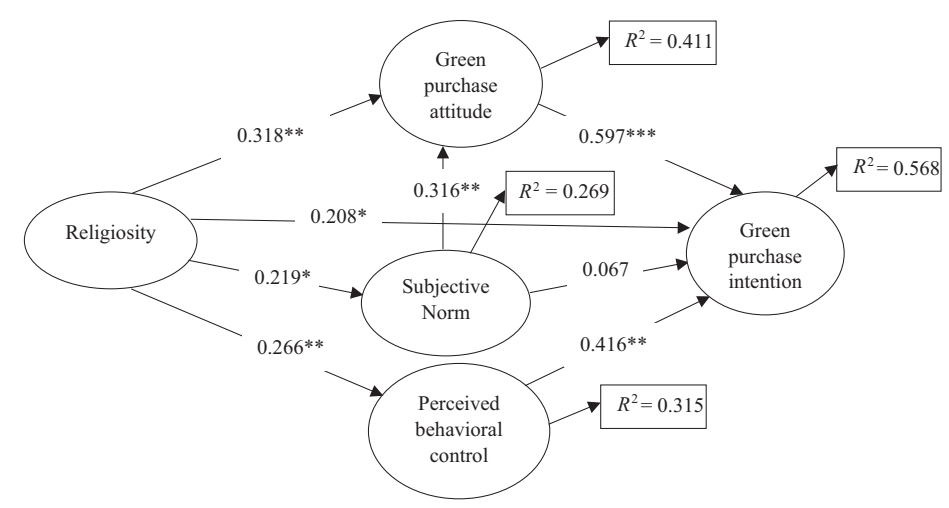

Notes: ${ }^{*} p<0.05 ;{ }^{* *} p<0.01 ;{ }^{* * *} p<0.001$ critical ration $>1.96$

\section{Table 4 Structural relationships and hypotheses testing}

\begin{tabular}{llcccc} 
Items & Parameter & Estimate & p-value & CR & Decision \\
\hline H1 & Religiosity $\rightarrow$ GPA & 0.318 & 0.008 & 3.177 & Supported \\
H2 & Religiosity $\rightarrow$ GPI & 0.208 & 0.017 & 3.264 & Supported \\
H3 & Religiosity $\rightarrow$ SN & 0.219 & 0.033 & 3.016 & Supported \\
H4 & Religiosity $\rightarrow$ PBC & 0.266 & 0.004 & 3.214 & Supported \\
H5 & GPA $\rightarrow$ GPI & 0.597 & 0.000 & 7.648 & Supported \\
H6 & SN $\rightarrow$ GPI & 0.067 & 0.411 & 0.657 & Not supported \\
H7 & SN $\rightarrow$ GPA & 0.316 & 0.009 & 3.117 & Supported \\
H8 & SN/GPA/GPI & & & & Supported \\
H9 & PBC $\rightarrow$ GPI & 0.416 & 0.004 & 5.532 & Supported
\end{tabular}

Notes: Green purchase attitude (GPA); green purchase intention (GPI); subjective norm (SN); perceived behavioural control (PBC)

RMSEA of 0.051. In other words, an adequate model fit was demonstrated. This step is illustrated in Figure 2 and Table 4 accordingly.

Wang et al. (2019b) noted that path coefficient of below 0.1 implies small effect; path coefficient of about 0.3 implies moderate effect; and path coefficient of 0.5 and above implies large effect. The obtained results are as follows:

- religiosity and GPA were positively and significantly correlated (moderate effect) ( $\beta=$ $0.318, p=0.008)$; thus, $H 1$ was accepted;

- religiosity and GPI were positively and significantly correlated (moderate effect) ( $\beta=$ $0.208, p=0.017$ ); thus, H2 was accepted;

- religiosity and $\mathrm{SN}$ were positively and significantly correlated (moderate effect) ( $\beta=$ $0.219, p=0.033$ ); thus, $H 3$ was accepted;

- religiosity and PBC were positively and significantly correlated (moderate effect) ( $\beta=$ $0.266, p=0.004)$; thus, $H 4$ was accepted;

- GPA and GPI were positively and significantly correlated (large effect) $(\beta=0.597, p=$ $0.000)$; thus, $H 5$ was accepted; 
- SN and GPA were positively and significantly correlated (moderate effect) ( $\beta=0.316$, $p=0.009)$; thus, $H 7$ was accepted; and

- PBC and GPI were positively and significantly correlated (moderate effect) ( $\beta=0.416$, $p=0.004)$; thus, $H 9$ was accepted.

On the other hand, the direct causal link between SN and GPI was found statistically insignificant $(p=0.411)$. Therefore, $H 6$ was rejected. Meanwhile, the mediation effect of GPA was determined based on the direct and indirect effects of the two-tailed significance test under bootstrapping at 0.05 level. In particular, the direct relationship between SN and GPI was found statistically insignificant $(p=0.318)$ whereas the indirect relationship between SN and GPI was found statistically significant ( $p=0.023)$. With that, attitude was found to exhibit full mediation on the relationship between $\mathrm{SN}$ and $\mathrm{GPI}$; thus, H8 was accepted.

\subsection{Analysis of variance}

Finally, ANOVA was performed to examine the influence of different religious affiliations on the different variables under study. The results of one-way ANOVA are tabulated in Table 5. The Scheffe alpha test was conducted for the classification of the differences of religious affiliation groups (Table 6). Firstly, the ANOVA results revealed no significant difference between religious affiliation for the cases of GPA and GPI $(p>0.05)$.

The ANOVA results revealed statistically significant effect of religious affiliation on religiosity, $[F(4,399)=6.209, p=0.000]$. Referring to the results of the Scheffe post-hoc test, the Islam group exhibited a statistically higher effect of religious affiliation on religiosity than the Taoism group at 0.05 level. The mean difference (I-J) between the religious affiliations of the Islam group and Taoism group was 0.70295. With that, the Islam group displayed a higher level of religiosity than the Taoism group. As for the comparison of religiosity between other religious affiliation groups, no statistical difference was found.

Meanwhile, the effect of religious affiliation on $\mathrm{SN}$ was found statistically significant [ $\mathrm{F}$ $(4,399)=3.31, p=0.011]$. The results of the Scheffe post-hoc test demonstrated that the Catholicism group exhibited a statistically higher effect of religious affiliation on SN than the Buddhism group ( $p=0.031)$. The mean difference $(I-J)$ between the Catholicism group and Buddhism group was 0.5558 . With that, the Catholicism group displayed a higher level of $\mathrm{SN}$ than the Buddhism group. As for the comparison of SN between other religious affiliation groups, no statistical difference was found.

\section{Table 5 One-way ANOVA samples test}

\begin{tabular}{llccccc} 
Dependent variable & Factor & Sum of squares & $d f$ & Mean square & $F$ & Sig. \\
\hline Religiosity & Religious affiliation & 19.796 & 4 & 4.949 & 6.209 & 0.000 \\
SN & Religious affiliation & 13.74 & 4 & 3.435 & 3.31 & 0.011 \\
PBC & Religious affiliation & 9.498 & 4 & 2.374 & 2.885 & 0.022
\end{tabular}

\section{Table 6 Post-hoc tests of religiosity, SN and PBC}

\begin{tabular}{lllcrc} 
Dependent variable & $\begin{array}{l}\text { (I) Religious } \\
\text { affiliation }\end{array}$ & $\begin{array}{l}\text { (J) Religious } \\
\text { affiliation }\end{array}$ & $\begin{array}{c}\text { Mean } \\
\text { difference (I-J) }\end{array}$ & Std. error & Sig. \\
\hline Religiosity & Islam & Taoism & 0.70295 & 0.15030 & 0.000 \\
SN & Catholicism & Buddhism & 0.55580 & 0.16943 & 0.031 \\
PBC & Islam & Buddhism & 0.42092 & 0.15928 & 0.039
\end{tabular}


Besides that, the effect of religious affiliation on PBC was found statistically significant [F $(4,399)=2.885, p=0.022]$. The results of Scheffe post-hoc test demonstrated that the Islam group exhibited a statistically higher effect of religious affiliation on PBC than the Buddhism group $(p=0.039)$. The mean difference $(I-J)$ between the Islam group and Buddhism group was 0.42092. With that, the Islam group displayed a higher level of PBC than the Buddhism group. As for the comparison of PBC between other religious affiliation groups, no statistical difference was found.

\section{Conclusion}

Focusing on the selection of environmentally friendly hotels in China, the extended TPB model that incorporated attitude, SN, PBC, intention and religiosity was empirically tested. In addition, this study also assessed the mediation effect of GPA on the influence of SN on GPI. This study empirically supports the validity of the theoretical foundations used, where a direct causal path of values or beliefs (i.e. religiosity), attitude and intention was found.

In addition, this study empirically demonstrated that highly religious consumers display more positive GPA in environmentally friendly hotel selection. This study also found that SN significantly and positively affected GPA and confirmed the mediation effect of GPA in the relationship between SN and GPI.

The present study supported the findings of previous studies where PBC significantly and positively influences GPI. Accordingly, the concept of perceived effectiveness of individuals' actions and their applications to environmentally friendly hotels were considered useful in promoting favourable attitudes and environmentally friendly hotel selection, making it a major driving force in the competitive marketing of hotels.

This study also demonstrated that Muslim consumers exhibited a higher level of religiosity than Taoist consumers and more Muslim consumers tend to select environmentally friendly hotels, as compared to Taoist consumers. Furthermore, Muslim consumers were found to display a higher level of PBC than Buddhist consumers. In other words, Muslim consumers display a higher willingness to visit environmentally friendly hotels, even when they encounter difficulties in environmentally friendly hotel selection. Last but not least, Catholic consumers in this study are more likely to obtain and disseminate insights on environmentally friendly hotels to Buddhist consumers. The key findings of this study are illustrated below:

- Religiosity positively and significantly influenced consumer GPA, SN, PBC and GPI to visit environmentally friendly hotels, respectively.

- GPA and PBC positively and significantly influenced consumer GPI to visit environmentally friendly hotels, respectively.

- SN positively and significantly influenced GPA. However, SN displayed an insignificant effect on GPI. Furthermore, GPA mediated the relationship between SN and intention to visit environmentally friendly hotels.

- Muslim consumers exhibited higher religiosity than Taoist consumers and higher PBC than Buddhist consumers. Further, Catholic consumers exhibited a higher SN than Buddhist consumers towards environmentally friendly hotel selection.

\section{Implications of the study}

\subsection{Theoretical implications}

Firstly, this study was among the first that empirically tested and validated the significant causal relationships of religiosity, attitude, SN, PBC and intention, using the highly rigorous method of SEM, as well as the relationship between religiosity and environmentally friendly 
hotel selection. These findings are especially significant for certain countries or regions with communities which profess a high degree of religiosity, such as the USA, China, Korea, Malaysia, India and Indonesia, as religiosity influences businesses, especially in the creation of consumer products and marketing strategies (Shah Alam et al., 2011).

Second, although numerous studies have acknowledged the direct effects of different aspects of religiosity on consumers' decision-making processes, there has been limited number of studies on the relationship between religiosity and green consumer behaviour, including environmentally friendly hotel selection, in China. The study outcomes offer an alternative perspective on the environmentally friendly hotel selection among the nonWestern consumers and valuable insights on the significance of the TPB model in assessing the influence of religiosity.

Moreover, the obtained results confirmed that there is a significant causal path from SN to GPA that leads to GPI. This particular finding in the non-Western context with the application of TRA or TPB was deemed noteworthy, as non-Western countries such as China, Japan and Korea have highly collectivistic communities, as compared to most Western countries (Wang et al., 2020). Non-Western consumers who are highly collectivistic tend to share their experience of the green products or services, such as environmentally friendly hotel selection, to their significant others. This study provided the basis for future research in replicating the quantitative data analyses and understanding the influence of religiosity on consumers' green purchase behaviour.

\subsection{Practical implications}

There were a number of practical implications for environmentally friendly hotels based on the findings of this study. Firstly, this study highlighted the need for hotel companies to develop different marketing strategies using religiosity as a segmentation variable as most consumers belong to different religious affiliations. The results of this study reaffirmed significant and positive relationships of religiosity as well as the significant relationships of attitude, SN and PBC with environmentally friendly hotel selection in China.

With the insights on the role of religiosity on the selection of environmentally friendly hotel gained from this study, different parts of China should be considered as new prospective markets. The implementation of green strategies for environmentally friendly hotels targeting customers from areas with highly religious populations such as the economically developed provinces in China such as Henan, Fujian and Jiangsu, which have a high proportion of Taoists, and well-known tourism provinces such as Shaanxi and Xinjiang where a majority of Muslim population can be found. This information reveals the distribution of religious groups for targeting by local and international hotels, which plans to market themselves as environmentally friendly hotels.

A better understanding of the different aspects of religions can benefit green hotel managers in developing effective marketing strategies for their business. For example, sensitising religious consumers to a pro-environmental worldview will promote a higher level of green consumption behaviour, including the selection of environmentally friendly hotels. Hotel managers can promote environmental values and perspectives through formal communication channels while focusing on green education initiatives.

The growing demand for religious tourism dictates that certain hotels are motivated to consider religious themes, because the religious tourism is a distinct type of tourism that undergoes a transformation phase (Collins-Kreiner, 2019). The development of unique and personalised products and services has become particularly significant to attract consumers of different religious affiliations in visiting environmentally friendly hotels. For instance, environmentally friendly hotels that adopt Buddhism theme in a Buddhistpopulated place can opt to provide organic and vegetarian food. Meanwhile, environmentally friendly hotels catering to Catholics and Protestants can opt to donate 
excess food and facilities for charity to improve their reputation. Besides that, the provision of prayer or meditation rooms and the use of certified halal products can attract Muslim consumers given their preferences for halal food and a healthier lifestyle.

\subsection{Limitations}

There were several limitations in this study. Firstly, data was collected through the use of an online survey. Despite the prevalent use of online survey, it poses several limitations. In this case, non-users were excluded. Secondly, the online survey was conducted in two different timeframes:

\section{1 October 2018 to 31 December 2018; and}

\section{1 November 2019 to 1 December 2019.}

The first round of online survey only managed to gather 283 respondents (small sample size). As a result, the second round of the online survey was conducted to gather more respondents for a more comprehensive representation of the target population (Saunders et al., 2011). Past studies identified demographic attributes as one of the most widely used methods to examine consumers' general or green purchase behaviour as such information is readily available and easy to apply for segmentation issues (Wang et al., 2019a). With that, the influence of demographic attributes as determinants of consumers' green purchase behaviour should be explored in future research.

\section{References}

Ahmad, A.N., Abd Rahman, A. and Ab Rahman, S. (2015), "Assessing knowledge and religiosity on consumer behavior towards halal food and cosmetic products", International Journal of Social Science and Humanity, Vol. 5 No. 1, pp. 10-14.

Ajzen, I. (1991), "The theory of planned behavior", Organizational Behavior and Human Decision Processes, Vol. 50 No. 2, pp. 179-211.

Ajzen, I. and Fishbein, M. (1975), Belief, Attitude, Intention, and Behavior: An Introduction to Theory and Research, Addison-Wesley, Reading, MA.

Albayrak, T., Aksoy, Ş. and Caber, M. (2013), "The effect of environmental concern and scepticism on green purchase behaviour”, Marketing Intelligence \& Planning, Vol. 31 No. 1, pp. 27-39.

Aman, A.L., Harun, A. and Hussein, Z. (2012), "The influence of environmental knowledge and concern on green purchase intention the role of attitude as a mediating variable", British Journal of Arts and Social Sciences, Vol. 7 No. 2, pp. 145-167.

Baker, M.A., Davis, E.A. and Weaver, P.A. (2013), "Eco-friendly attitudes, barriers to participation, and differences in behavior at green hotels", Cornell Hospitality Quarterly, Vol. 55 No. 1, pp. 89-99.

Borzooei, M. and Asgari, M. (2014), "The effect of religious commitment on halal Brand relationship and purchase intention", The International Journal's Research Journal of Economics and Business Studies, Vol. 3 No. 4, pp. 14-19.

Burstein, D. (2011), "Marketing optimisation: how to determine the proper sample size", available at: https://marketingexperiments.com/a-b-testing/testing-sample-size\#comments (accessed 6 May, 2011).

Byrne, B.M. (2016), Structural Equation Modeling with AMOS: Basic Concepts, Applications, and Programming, Routledge, London.

Chatzidakis, A., Hibbert, S. and Smith, A.P. (2007), "Why people don't take their concerns about fair trade to the supermarket: the role of neutralisation", Journal of Business Ethics, Vol. 74 No. 1, pp. 89-100.

Chen, M.-F. and Tung, P.-J. (2014), "Developing an extended theory of planned behavior model to predict consumers' intention to visit green hotels", International Journal of Hospitality Management, Vol. 36, pp. 221-230.

Chen, T.B. and Chai, L.T. (2010), "Attitude towards the environment and green products: consumers' perspective", Management Science and Engineering, Vol. 4 No. 2, pp. 27-39. 
Choi, Y. (2010), "Religion, religiosity, and South Korean consumer switching behaviors", Journal of Consumer Behaviour, Vol. 9 No. 3, pp. 157-171.

Coleman, L.J., Bahnan, N., Kelkar, M. and Curry, N. (2011), "Walking the walk: how the theory of reasoned action explains adult and student intentions to go green", Journal of Applied Business Research (JABR), Vol. 27 No. 3, pp. 107-116.

Collins-Kreiner, N. (2019), "Pilgrimage tourism-past, present and future rejuvenation: a perspective article”, Tourism Review, Vol. 75 No. 1, pp. 145-148.

Connelly, L.M. (2008), "Pilot studies", Medsurg Nursing, Vol. 17 No. 6, pp. 411-413.

Dawes, J. (2008), "Do data characteristics change according to the number of scale points used? An experiment using 5-point, 7-point and 10-point scales", International Journal of Market Research, Vol. 50 No. 1, pp.61-77.

De Run, E.C., Butt, M.M., Fam, K.-S. and Jong, H.Y. (2010), "Attitudes towards offensive advertising: Malaysian Muslims' views”, Journal of Islamic Marketing, Vol. 1 No. 1, pp. 25-36.

De Vaus, D. (2013), Surveys in Social Research, Routledge, London.

Engelland, B.T. (2014), "Religion, humanism, marketing, and the consumption of socially responsible products, services, and ideas: introduction to a special topic section", Journal of Business Research, Vol. 67 No. 2, pp. 1-4.

Guo, C., Webb, N.J., Abzug, R. and Peck, L.R.A. (2013), "Religious affiliation, religious attendance, and participation in social change organisations", Nonprofit and Voluntary Sector Quarterly, Vol. 42 No. 1, pp. 34-58.

Hair, J.F., Black, W.C., Babin, B.J. and Tatham, R.L. (2010), Multivariate Data Analysis: A Global Perspective, Pearson Prentice Hall, Upper Saddle River, NJ.

Han, H. (2015), "Travelers' pro-environmental behavior in a green lodging context: converging value-belief-norm theory and the theory of planned behavior", Tourism Management, Vol. 47, pp. 164-177.

Han, H. and Yoon, H.J. (2015), "Hotel customers' environmentally responsible behavioral intention: impact of key constructs on decision in green consumerism", International Journal of Hospitality Management, Vol. 45, pp. 22-33.

Han, H., Hsu, L.-T. and Sheu, C. (2010), "Application of the theory of planned behavior to green hotel choice: testing the effect of environmental friendly activities", Tourism Management, Vol. 31 No. 3, pp. 325-334.

Hill, R. (1998), "What sample size is 'enough' in internet survey research", Interpersonal Computing and Technology: An Electronic Journal for the 21st Century, Vol. 6 Nos 3/4, pp. 1-12.

Ho, R. (2006), Handbook of Univariate and Multivariate Data Analysis and Interpretation with SPSS, CRC Press, New York, NY.

Jiang, Y. and Gao, Y. (2019), "Factors that influence potential green hotel customers' decision-making process - evidence from China", Journal of China Tourism Research, Vol. 15 No. 4,

Kasliwal, N. and Agarwal, S. (2015), "A study on Indian consumers' attitude and choice of preferences for green attributes of the hotel industry", Prabandhan: Indian Journal of Management, Vol. 8 No. 1, pp. 21-33.

Khraim, H. (2010), "Measuring religiosity in consumer research from an Islamic perspective", Journal of Economic and Administrative Sciences, Vol. 26 No. 1, pp. 52-78.

Kirmani, M.D. and Khan, M.N. (2016), "Environmental concern to attitude towards green products: evidences from India", Serbian Journal of Management, Vol. 11 No. 2, pp. 159-179.

Kline, R.B. (2015), Principles and Practice of Structural Equation Modeling, Guilford publications, New York, NY.

Kumar, B., Manrai, A.K. and Manrai, L.A. (2017), "Purchasing behaviour for environmentally sustainable products: a conceptual framework and empirical study", Journal of Retailing and Consumer Services, Vol. 34, pp. 1-9

Lari, L.A.D.A., Iyanna, S. and Jabeen, F. (2019), "Islamic and Muslim tourism: service quality and theme parks in the UAE", Tourism Review, Vol. 75 No. 2, pp. 402-413. 
Lau, T.-C. (2010), "Towards socially responsible consumption: an evaluation of religiosity and money ethics", International Journal of Trade, Economics and Finance, Vol. 1 No. 1, pp. 32-35.

Madni, A.R., Hamid, N.A. and Rashid, S.M. (2016), "An association between religiosity and consumer behavior: a conceptual piece", The Journal of Commerce, Vol. 8 No. 3, pp. 58-65.

Maichum, K., Parichatnon, S. and Peng, K.-C. (2016), "Application of the extended theory of planned behavior model to investigate purchase intention of green products among Thai consumers", Sustainability, Vol. 8 No. 10, pp. 1077-1097.

Martin, W.C. and Bateman, C.R. (2014), "Consumer religious commitment's influence on ecocentric attitudes and behavior", Journal of Business Research, Vol. 67 No. 2, pp. 5-11.

Mas'od, A. and Chin, T.A. (2014), "Determining socio-demographic, psychographic and religiosity of green hotel consumer in Malaysia", Procedia - Social and Behavioral Sciences, Vol. 130 No. 2014, pp. 479-489.

Mawdsley, E. (2004), "India's middle classes and the environment", Development and Change, Vol. 35 No. 1, pp. 79-103.

Meyers, L.S., Gamst, G. and Guarino, A.J. (2006), Applied Multivariate Research: Design and Interpretation, Sage, London.

Minton, E.A., Kahle, L.R. and Kim, C.-H. (2015), "Religion and motives for sustainable behaviors: a crosscultural comparison and contrast", Journal of Business Research, Vol. 68 No. 9, pp. 1937-1944.

Mohamad, Z.Z., Arifin, T.R.T., Samsuri, A.S. and Munir, M.F.M.B. (2014), "Intention to visit green hotel in Malaysia: the impact of personal traits and marketing strategy", International Journal of Business and Social Science, Vol. 5 No. 7, pp. 167-173

Mokhlis, S. (2009), "Relevancy and measurement of religiosity in consumer behavior research", International Business Research, Vol. 2 No. 3, pp. 75-84.

Muzaffar, N. (2015), "Developing an extended model of theory of planned behavior to explore green purchase behavior of Pakistani consumers", American Journal of Business and Management, Vol. 4 No. 2, pp. 85-101.

Neuman, W.L. (2002), Social Research Methods: Qualitative and Quantitative Approaches, Pearson Education, London.

Patel, M. (2012), "Influence of religion on shopping behavior of consumers-an exploratory study", Abhinav National Monthly Refereed Journal of Research in Commerce \& Management, Vol. 1 No. 5 , pp. 68-78.

Paul, J., Modi, A. and Patel, J. (2016), "Predicting green product consumption using theory of planned behavior and reasoned action", Journal of Retailing and Consumer Services, Vol. 29, pp. 123-134.

Rahman, I. and Reynolds, D. (2016), "Predicting green hotel behavioral intentions using a theory of environmental commitment and sacrifice for the environment", International Journal of Hospitality Management, Vol. 52, pp. 107-116.

Sarmah, H., Hazarika, B.B. and Choudhury, G. (2013), "An investigation on effect of bias on determination of sample size on the basis of data related to the students of schools of Guwahati", International Journal of Applied Mathematics and Statistical Sciences, Vol. 2 No. 1, pp. 33-48.

Saunders, M., Lewis, P. and Thornhill, A. (2011), Research Methods for Business Students, Pearson Education, Harlow.

Shah Alam, S., Mohd, R. and Hisham, B. (2011), "Is religiosity an important determinant on Muslim consumer behaviour in Malaysia?", Journal of Islamic Marketing, Vol. 2 No. 1, pp. 83-96.

Shin, J., Park, M., Moon, M. and Kim, M. (2011), "Does religiosity affect on consumer's socialisation agent and shopping orientation", 2010 International conference on e-business, management and economics, International Association of Computer Science and Information Technology, Hong Kong, pp. 154-158.

Suki, N.M. and Suki, N.M. (2015), "Does religion influence consumers' green food consumption? Some insights from Malaysia", Journal of Consumer Marketing, Vol. 32 No. 7, pp. 551-563.

Sutikno, V. and Margaretha, S. (2020), "Young consumer's purchase intention toward environmentally friendly products in Indonesia: expanding the theory of planned behavior", Advances in Economics, Business and Management Research, Vol. 115, pp. 36-40. 
Tabachnick, B.G. and Fidell, L.S. (2007), Using Multivariate Statistics, Allyn \& Bacon/Pearson Education, Boston, MA

Teeroovengadum, V. (2019), "Environmental identity and ecotourism behaviours: examination of the direct and indirect effects", Tourism Review, Vol. 74 No. 2, pp. 280-292.

Vazifehdoust, H., Taleghani, M., Esmaeilpour, F., Nazari, K. and Khadang, M. (2013), "Purchasing green to become greener: factors influence consumers' green purchasing behavior", Management Science Letters, Vol. 3 No. 9, pp. 2489-2500.

Wang, L., Wong, P.P.W. and Elangkovan, N.A. (2019a), "The demographic impact of consumer green purchase intention toward green hotel selection in China", Tourism and Hospitality Research, Vol. 20 No. 2, pp. 210-222.

Wang, L., Wong, P.P.W. and Elangkovan, N.A. (2019b), "The influence of religiosity on consumer's green purchase intention towards green hotel selection in China", Journal of China Tourism Research, pp. 1-27.

Wang, L., Wong, P.P.W., Elangkovan, N.A. and Chee, W.M. (2019c), "Green hotel selection of Chinese consumers: a planned behavior perspective", Journal of China Tourism Research, Vol. 15 No. 2, pp. $192-212$.

Wang, L., Wong, P.P.W. and Elangkovan, N.A. (2020), "Antecedents of green purchase behaviour: an examination of altruism and environmental knowledge", International Journal of Culture, Tourism and Hospitality Research, Vol. 14 No. 1, pp. 63-82.

Worthington, E.L., Jr. Wade, N.G., Hight, T.L., Ripley, J.S., McCullough, M.E., Berry, J.W., Schmitt, M.M., Berry, J.T., Bursley, K.H. and O'connor, L. (2003), "The religious commitment inventory-10: development, refinement, and validation of a brief scale for research and counseling", Journal of Counseling Psychology, Vol. 50 No. 1, pp. 84-96.

Yadav, R. and Pathak, G.S. (2016), 'Young consumers' intention towards buying green products in a developing nation: extending the theory of planned behavior", Journal of Cleaner Production, Vol. 135, pp. 732-739.

\section{About the authors}

Lei Wang is a Lecturer at the Faculty of Hospitality and Tourism, School of Management, Xuzhou University of Technology, China. He has received his master's degree of Master in Leisure and Tourism Management from the Limkokwing University of Creative Technology, Malaysia. He obtained his PhD in Hospitality and Tourism from the Taylor's University, Malaysia. His research focuses on sustainability of tourism management, religion/religiosity, consumer decision-making, consumer loyalty and green purchase behaviour. Lei Wang is the corresponding author and can be contacted at: 1136603668@qq.com

Philip Pong Weng Wong is a Senior Lecturer at the School of Hospitality, Sunway University, Malaysia. He has received his master's degree from the University of Nevada Las Vegas, USA. He obtained his PhD from the University Putra Malaysia. His research interests are destination marketing, destination branding, destination competitiveness and destination loyalty.

For instructions on how to order reprints of this article, please visit our website: www.emeraldgrouppublishing.com/licensing/reprints.htm

Or contact us for further details: permissions@emeraldinsight.com 